\title{
An overview of the Italian contribution to the international multisite SPRISTAD study on psychotherapy training
}

\author{
Irene Messina, ${ }^{1,2}$ Salvo Gullo, ${ }^{1,3}$ Omar Carlo Gioacchino Gelo, ${ }^{1,3-5}$ Cecilia Giordano, ${ }^{1,3}$ Silvia Salcuni ${ }^{1,6}$ \\ IItaly Area Group of the Society for Psychotherapy Research (SPR-IAG), Italy; ${ }^{2}$ Department of Economics, Universitas Mercatorum, \\ Rome, Italy; ${ }^{3}$ Department of Psychological, Pedagogical, Exercise and Education Sciences, University of Palermo, Italy; \\ ${ }^{4}$ Department of History, Society and Human Studies, University of Salento, Italy; ${ }^{5}$ Department of Psychotherapy Science, Sigmund \\ Freud University, Vienna, Austria; ${ }^{6}$ Department of Developmental Psychology and Socialization, University of Padua, Italy
}

\begin{abstract}
The Interest Section on Therapist Training and Development of the Society for Psychotherapy Research (SPRISTAD) has launched a multisite collaborative longitudinal study of psychotherapy trainees' development, a large-scale study involving a number of countries all over the world. In the present article, we present an overview of the early Italian contribution to the SPRISTAD study, based on preliminary paper-and-pencil data collection. Our preliminary findings showed cross-sectional differences at different years of training and two-years longitudinal changes in trainees' perceived development. Moreover, trainees' characteristics such as their motivation, relational manner, current life, and personal background have shown to deserve attention in research on trainees' development. These findings encourage the continuation of the SPRISTAD online data collection.
\end{abstract}

Key words: SPRISTAD; Italy; Psychotherapy training; Psychotherapy trainees; Therapist development.

\section{Introduction}

The Interest Section on Therapist Training and Development of the Society for Psychotherapy Research

Correspondence: Irene Messina, Department of Economics, Universitas Mercatorum, Via Mattei 10, 00186, Rome, Italy.

Tel. +39.3202685626.

E-mail: irene.messina@unimercatorum.it

Citation: Messina, I., Gullo, S., Gelo, O. C. G., Giordano, C., \& Salcuni, S. (2019).An overview of the Italian contribution to the international multisite SPRISTAD study on psychotherapy training. Research in Psychotherapy: Psychopathology, Process and Outcome, 22(3), 379-388. doi: 10.4081/ripppo.2019.418

Acknowledgements: the authors would like to thank Centro Psicologia Dinamica (CPD), Centro Padovano di Terapia Familiare (CPTF), Associazione Terapia Cognitiva (ATC) and the Institute of Constructivist Psychology (ICP).

Contributions: IM, manuscript writing; SG, OCGC, CG, SS, manuscript reviewing.

Conflict of interest: the authors declare no potential conflict of interest.

Received for publication: 9 July 2019.

Revision received: 14 October 2019.

Accepted for publication: 19 October 2019.

This work is licensed under a Creative Commons Attribution NonCommercial 4.0 License (CC BY-NC 4.0).

${ }^{\circ}$ Copyright: the Author(s), 2019

Licensee PAGEPress, Italy

Research in Psychotherapy:

Psychopathology, Process and Outcome 2019; 22:379-388

doi:10.4081/ripppo.2019.418
(SPRISTAD) is the main international network devoted to the investigation of psychotherapy trainees' development. Its purposes have been declared as follows: i) to promote scientific research on the processes and outcomes of psychotherapist training and development; ii) to facilitate collaboration among members in planning, discussion, and conduct of methodologically sound, theoretically balanced, and clinically relevant studies on the selection, training, supervision, continuing education, and professional development of psychotherapists; and iii) to support the dissemination of research-based knowledge of therapist training and development for the benefit of scientific, clinical, and mental health policy communities (Society for Psychotherapy Research, 2011).

Previous studies have focused on therapist development without attention to the role of psychotherapy training in promoting such development. Among these studies, the most important has been conducted by the Society for Psychotherapy Research (SPR) Collaborative Research Network - ancestor of SPRISTAD - which have identified important aspects of the development of more than 12,000 psychotherapists from 30 countries in the world (Orlinsky et al., 1999; Orlinsky, Rønnestad, \& the SPR Collaborative Research Network, 2005; Orlinsky, Rønnestad, \& Willutzki, 2010). While it has been shown that the perception of therapists' development varies between beginner and experienced clinicians - with higher perceived therapeutic mastery with increasing years in psychotherapy practice - the role of psychotherapy training in such development remains uninvestigated. At the present, the documentation of trainees' development during their psychotherapy training has been evaluated only in small groups 
of either doctoral students or psychotherapy trainees (Barnfield et al., 2007; Bennett-Levy \& Beedie, 2007; Hill et al., 2015), or considering specific therapeutic abilities in single real or simulates sessions (for a review see Hill \& Knox, 2013). Moreover, enormous differences exist in psychotherapy training programs and legal requirements to become psychotherapist across different countries, and data concerning the effects of these differences in terms of training effectiveness are not available. Thus, a comprehensive evaluation of training effectiveness in promoting psychotherapists' development is still missing.

In order to overcome the limitations of previous research and to address neglected aspects of psychotherapy training research, in 2012 SPRISTAD launched the international multisite Collaborative Longitudinal SPRISTAD Study of Psychotherapy Trainees, a large-scale study involving a number of countries all over the world (by mid2018, researchers and training institutes coming from 19 countries have been involved). This study has the purpose to realize a massive online longitudinal data collection involving several countries in the world. The aims of SPRISTAD study have been defined as follows: i) tracking progressive changes in trainees over time; ii) identifying the factors that facilitate or impede trainee development; and iii)relating therapist characteristics and development to psychotherapy process and outcome (Orlinsky et al., 2015, p. 22).

In line with the above-declared purposes, three core instruments have been included in the online data collection system (Orlinsky et al., in preparation). The first is the Training Program Description Form (TPDF), completed by the training director (or a staff person) to give information concerning the main characteristics of the training program. This instrument is particularly important for the documentation of differences between training institutes located in different countries in the world. The second instrument is the Trainee Background Information Form (TBIF), completed by participating trainees once at the beginning of the study, to describe aspects of their professional and personal lives that are not expected to change over time and that may influence their development. Third, the Trainee Current Practice Report (TCPR) is the core of the longitudinal evaluation, used to track change over time, focused primarily on aspects of trainees' therapeutic practice and professional development.

In the present article, we present an overview of the early Italian contribution to the SPRISTAD study, based on data collected using preliminary paper-and-pencil versions of SPRISTAD questionnaires (a summary of considered studies is presented in Table 1). We review these data - presented in previous research articles, national and international conferences-discussing their implications in terms of the potentiality of SPRISTAD project and considering the actual sensitivity of SPRISTAD instrument for the evaluation of the declared research goals.

\section{Psychotherapy training institutes in the Italian context}

The European Association for Psychotherapy (EAP, 2017) describe psychotherapy situation regulated by law (Law 56/1989) and the roles for the exercise of the psychotherapeutic activity in Italy, which is subjected to specific training, to be acquired after obtaining a degree in psychology or in medicine and after the admission to the professional register. It's a four years training which includes adequate theoretical and practice training in psychotherapy. The training program generally comprises 500 hours per year for classes and practical activities, such as supervision, tutoring and practical workshops, and 100 hours per year for traineeship carried out in qualified structures and services (Giannone, Giordano, \& Di Blasi, 2015). These training courses are activated in consideration of the Italian law (10 March 1982, n. 162), by universities or private institutes (recognized by the Italian Ministry of Education, MIUR)allowed to organize training in psychotherapy by the Italian law (11 December 1998, n. 509 and 21 January 2019, n. 50). The postgraduate training is offered by Universities and Private Psychotherapy Schools recognized by the Italian Ministry of Education (MIUR). Psychotherapy approaches accepted are Psychodynamic, Humanistic, Psycho Body Therapy, SystemicFamily Therapy, Cognitive-Behavioural. Nowadays, in Italy 148 private psychotherapy schools of different theoretical approach have been recognized by MIUR in Italy (EAP, 2017). In 2014, Italy counted 37.000 psychotherapist: $2 / 3$ psychologists and $1 / 3$ medical doctors (about one psychotherapist on 1.600 persons in Italy). The educational trends of Psychology Schools counted over 50.000 new graduates in 2016, and 25.000 of them had a specialization in psychotherapy. Personal analysis is not mandatory, but may be required by some psychodynamically-oriented schools. The training remains largely $(80 \%)$ a prerogative for private institutions that historically had and still have the know-how about the training for psychotherapists, beyond academic fields where programs are traditionally oriented to provide theoretical knowledge.

To date, 7 private psychotherapy schools signed the contract to be part of SPRISTAD project: Centro Psicologia Dinamica (CPD; psychodynamic psychotherapy), Centro Padovano di Terapia Familiare (CPTF; family therapy), Associazione Terapia Cognitiva (ATC; cognitive psychotherapy), Institute of Constructivist Psychology (ICP; cognitive psychotherapy), Confederazione di Organizzazioni Italiane per la Ricerca Analitica sui Gruppi (COIRAG; group psychoanalytic psychotherapy), Società Italiana di Psicoterapia Psicoanalitica (SIPP; psychoanalytic psychotherapy), Società Adleriana Italiana Gruppi e Analisi (SAIGA; individual psychology), and Istituto di Ricerca in Psicoterapia Psicoanalitica (IREP, psychoanalytic psychotherapy). Preliminary data have been collected in four training programs: CPD, CPTF, ATC and ICP. 


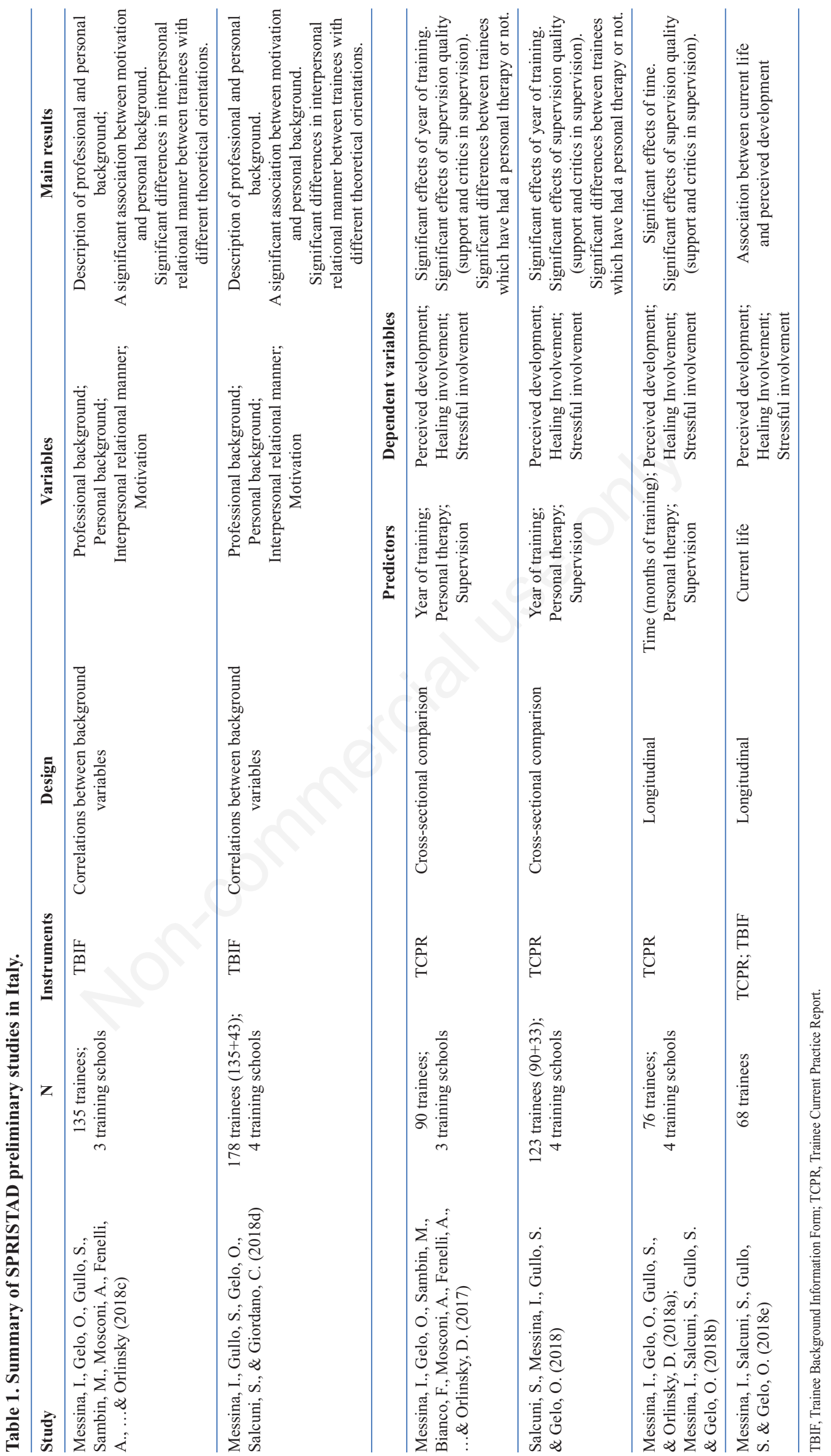




\section{Trainees' background}

Individuals who start a psychotherapy training can be very different in terms of previous professional and personal experiences. They may have different relational attitudes and motivations to become psychotherapists. These and other individual differences may strongly influence their development during the training, and the knowledge of these influences may have important implications for the implementation of training programs. Due to the importance of the person of psychotherapy trainees', relating psychotherapy trainees' characteristics and their development is another important purpose of the SPRISTAD study. The TBIF has been constructed to describe aspects of trainees' professional and personal lives that are pre-existent to the beginning of the training and that are not expected to change over time. It allows the collection of the following information: i) Basic information such as demographic information (including age, gender, nationality, etc.) and training program information (such as theoretical approach, duration, etc.); ii) Professional background such as information concerning previous academic degrees, previous working experiences and previous experiences in doing psychotherapy/counseling; iii) Personal background (country, religion, economic circustamcies, family components, etc.), including ratings of life experiences in terms of a sense of being cared (item When growing up, how much did you experience a sense of being genuinely cared for and supported?), family functioning (item When growing up, how much did the family you grew up in function well emotionally and psychologically?), and experienced trauma or abuse in childhood (item When growing up, did you experience any emotionally significant trauma or abuse?); iv) Actual life (marital status, children, economic conditions, etc.), including satisfaction in actual life (item How satisfying is your own life at the present time?) and stress in actual life (item How stressful is your life at the present time?); v) Previous experiences in personal therapy (amount of therapy, duration, orientation, etc.); vi) Interpersonal relational manner in close relationships consisting in the rating of a list of adjectives (for example, Accepting, Accommodating, Authoritative, Bold, etc.); vii) Motivation in starting a psychotherapy training investigated with the open question What are the main influences and events in life that led you to seek training as a psychotherapist?; and viii) Strength and limitations as therapist (open questions What do you view as your main personal and/or professional strengths or talents for work as an effective therapist/counselor? and What do you view as the main personal and/or professional limitations you need to overcome to work effectively as a therapist/counselor?).

The first step toward the investigation of the association between trainees' individual differences and their influences on their development is the description of these differences. In the first study on the background of Italian psychotherapy trainees personal and professional background, motivation, and interpersonal style have been explored in a group of 135 Italian trainees with different theoretical approaches (psychodynamic, systemic, and cognitive-behavioural) which completed the TBIF (Messina et al., 2018c). We describe below the main findings emerged in this study. First, regarding prior professional background, most of the trainees considered in this study had a master's degree in psychology, with few exceptions of trainees with a medical background. Moreover, most trainees reported having had previous training or work in different careers or professions and previous experiences relevant to psychotherapy/counseling. All these data are not surprising due to the legal requirements to start a psychotherapy training in the Italian context (master's degree in psychology or medicine, and one year clinical or research internship after the master's degree in psychology before starting a psychotherapy training).

Regarding the personal background, trainees varied in their ratings of life experiences in terms of a sense of being cared, family functioning and experienced trauma or abuse in childhood. They varied also in the description of their relational manner, although higher ratings were observed for adjectives such as friendly, introspective, intimate, accepting, passionate, determined, intuitive, and warm, suggesting that these characteristics - often reported as characteristic for effective psychotherapists may be pre-existent in persons that start a psychotherapy training. Anyway, all these variables may be relevant for therapist development and they should be considered in future researches on psychotherapy training programs.

Another relevant issue emerged from this study is motivation. In this case, the research question would be: Why do people start psychotherapy training? Intriguingly, it was observed that negative personal experiences of trainees are the most frequently reported motivation in undertaking psychotherapy training (almost $45 \%$ of trainees reported this category of motivation). For example, previous experiences with family members or friends with psychological problems were often reported as motivation to become a psychotherapist. Moreover, trainees who gave a negative personal experience as motivation to start the training reported worse experiences in childhood. This result has been confirmed in an update based on an enlarged sample of 178 trainees, coming from 4 training programs (psychodynamic, systemic, cognitive-behavioural, and constructivist), presented at the international SPR meeting in Amsterdam (Messina, Gullo, Gelo, Salcuni, \& Giordano, 2018d) and at the SPR-IAG in Palermo (Messina, Salcuni, Gullo, \& Gelo, 2018e). In the update, it has been confirmed that negative experiences in the personal background are most frequently reported motivation to start a psychotherapy training ( $47.6 \%$ of participants reported this category of motivation) and that this category of motivation was associated to less care, less familiar functioning, and more traumatic experiences in 
childhood. The importance of this variable recalls the idea that a therapist who have experienced personal suffering and internal conflicts may become more aware, and able to understand and help others: a well-known idea in the literature, named the concept wounded healer (Jung, 1951). However, beyond theoretical considerations and qualitative case studies (e.g.: Barnett, 2007; Farber, Manevich, Metzger, \& Saypol, 2005; Messina et al., 2018f), statistical analysis of the impact of therapists' personal history variables on their development and on their effectiveness as therapists are missing in the literature. Early empirical data on therapist background confirm that this variable deserves attention for the understanding of therapist development, longitudinal analysis of the influence of personal background on trainees' perceived development have been planned as one of the future steps of SPRISTAD study (but see also early Results in Longitudinal data section).

Also other categories of motivations were often reported by trainees (consider that trainees may report more than one motivation): personal predisposition, such as being an emphatic or altruist person ( $42 \%$ of trainees mentioned this category), motivations related to their professional background, as for example the desire to acquire practical competencies after academic theoretical training $(25 \%)$, theoretical interest and curiosity for the functioning of human mind and human relationships (23\%), personal development, as for example become more aware of personal psychological conflicts and relational difficulties (14\%), and professional development included motivations associated with the desire to improve one's professional abilities as a psychotherapist, as for example improve technical competencies in psychotherapy practice $(14 \%)$. The impact of different categories of motivations on trainees' development should be investigated in future studies.

Finally, in this study differences between trainees with different theoretical orientation have been reported. Although theoretical preferences were not associated with trainees' personal background, cognitive-behavioral trainees reported lower motivations associated with their personal backgrounds, such as motivations concerning personal development and negative personal experiences. These results may reflect the preference for trainings that attribute minor importance to personal therapy.

It has been affirmed that therapists' theoretical preferences may be considered as manifestations of their personality (McConnaughy, 1987). In line with this idea, trainees that have chosen different approaches resulted statistically different in their manner in close personal relationships. For example, among the orientations considered in Messina et al. 2018c (psychodynamic, cognitive-behavioral, and systemic), psychodynamic trainees reported being more accepting compared to trainees of other approaches, whereas cognitive-behavioural trainees reported being less introspective compared to the others. Even if the consideration of an exiguous number of trainees does not allow to draw conclusions about the interpersonal manner of trainees with different orientations, these data account the existence of systematic differences between trainees with different orientations. Again, this can be a variable which deserves attention for future investigations.

\section{Tracking changes in trainees over time}

Tracking progressive changes in psychotherapy trainees over time is the main goal of SPRISTAD. With this aim, the TCPR has been created to monitor changes over time in trainees' perception of their development as psychotherapists, with a focus on their therapeutic practice and professional development. It includes mixed quantitative and open ended questions to collect information concerning the following dimensions: i) Basic anagraphic information about the trainee and general information about the training; ii) Practice experience (patients, settings, theoretical preference, etc.); iii) Relational manner with patientsconsisting in the rating of a list of adjectives (for example, Accepting, Accommodating, Authoritative, Bold, etc.); iv) Perceived development since the beginning of the training, which include the rating of the following items: overall change, change as improvement, change as decline, extent of having overcome past limitations, satisfaction with development to date, and extent of having realized one's potential as a therapist; v) Clinical skills which include the rating of several technical and relational skills in doing therapy (e.g., How effective are you at engaging patients/clients in a working alliance?); vi) Difficulties in psychotherapy practice which include the rating of several common difficulties in doing therapy (e.g., Bogged down with a client in a relationship that seems to go nowhere); vii) Coping strategies in case of difficulties with patients, consisting in the rating of how often constructive (e.g., consulting a supervisors) and avoidant (e.g., postponing dealing with the problem) coping strategies are used in case of difficulties in doing therapy; viii) In-session experiences consisting in the rating of a list of adjectives describing experienced feelings during psychotherapy sessions (for example, Absent, Anxious, Inspired, etc.); ix) Supervision (quantity, perceived support and critics, theoretical orientation, etc.); x) Personal therapy (quantity, perceived benefit, theoretical orientation, etc.); xi) Actual development as therapist consisting in the rating of items concerning perceived development at the present; xii) Open questions concerning strength, limitation and recent change in therapeutic practice; xiii) Experiences as part of the training(supervision, case discussion, role-playing, etc.) and their impact; xiv) Actual life (stress, satisfaction and emotional functioning). Among these numerous variables considered by the questionnaire, early investigations have been focused on Perceived Development since the starting of the training 
and several aspects of the experience of therapeutic work at the present evaluated as part of two dimensions: healing involvement and stressful involvement (for psychometric characteristic of these dimension see Messina et al., 2017; Kolinsky et al., 2005). Healing involvement include the following factors: clinical skills (10 items),constructive coping with difficulties in doing therapy (6 items), flow during therapy sessions ( 3 items, in-session experiences inspired, stimulated, engrossed, and challenged), and agency (3 itemsn-session experiences skilful, effective, and wise) and warmth (4 items, in-session experiences warm, accepting, friendly, and tolerant) as aspects of relational manner with patients. Stressful involvement is evaluated through multiple-item scales including clinical difficulties in practice (12 items), avoidant coping with difficulties in doing therapy (6 items), and in-session feelings of anxiety (4 items, in-session experiencesanxious, overwhelmed, pressured and trapped), and in-session boredom (3 items, in-session experiences absent, bored, and drowsy).In early investigations, all these variables have been considered as the effect of several independent variables evaluated in the TCPR. First, the effect of time in training (in months or years of training) has been considered as the main independent variable. Second, the core experiences of supervision and personal therapy have been considered as predictors including both quantitative aspects(having had supervision and personal therapy and the number of hours devoted to such activities) and qualitative aspects (such as benefit perceived as an effect of personal therapy, perceived support and criticisms in supervision).

\section{Cross-sectional data}

Although the TCPR has been developed with the purpose of longitudinal evaluations, preliminary cross-sectional studies have used this questionnaire to compare psychotherapy trainees at different steps of their training and evaluated one time. A first study tested the differences between 90 Italian trainees at different years training, coming from 3 different training institutes (dynamic, systemic, and cognitive) (Messina et al., 2017).According to the results of this study, more experienced trainees reported significantly higher levels in important dimensions of perceived change, such as the perceived overall change during the training and progress in realizing one's therapeutic potential. More experienced trainees reported also their therapeutic work with patients more as a healing involvement (higher relational agency and feelings of flow during therapy sessions) and less as a stressful involvement (less frequent difficulties in practice and less frequent feelings of anxiety and boredom in psychotherapy sessions).

Beyond time per se, this early study showed the importance of supervision and personal therapy. The feeling to be supported in supervision was negatively associated with perceived decline and positively with expressed sat- isfaction with the development. On the other hand, feeling to be criticized in supervision was significantly associated with a stressful involvement in doing psychotherapy, with more difficulties in practice and more use of coping strategies based on avoidance. Instead, the amount of supervision in terms of hours per month was not predictive of developmental variables.

Finally, controlling for time, having had personal therapy was also associated with perceived development (overall change and experience of that change as progress or improvement) and with important aspects of healing involvement, such as clinical skills and relational warmth with patients. Again, the quantitative aspect of time in therapy was not relevant, whereas perceived benefit in personal therapy was predictive of almost all the variables of perceived development (perceived change, perceived improvement, overcoming part limitations, satisfaction with development, realization of potential) and healing involvement (clinical skills, use of constructive coping strategies against difficulties, in-session flow and relational agency).

An update of this data collection has been presented in the Italy Area Group of the Society for Psychotherapy Research (SPR-IAG) conference in 2018 in Palermo (Messina et al., 2018e). In this case, a group of 123 traineeswas reached, recruited in four different psychotherapy institutes (dynamic, systemic, cognitive and constructivist). As expected, all previous results were confirmed with an improvement of the statistical power of the study. Moreover, new significant effects have emerged in this update: first, years of training have predicted also fewer difficulties in psychotherapy practice; second, perceived support in supervision was associated with overall perceived change. Thus, almost all variables evaluated in the TCPR are important markers of developmental changes in trainees at different steps of psychotherapy training.

\section{Longitudinal data}

Tracking psychotherapy trainees' change over time in training is the main and more ambitious aim of SPRISTAD. In 2018, early two-years longitudinal data have been collected in the Italian context and presented to the International SPR meeting in Amsterdam (Messina et al., 2018a) and in the SPR-IAG conference in Palermo (Messina et al., 2018b). A group of 76 Italian trainees was involved, recruited in four different psychotherapy institutes (dynamic, systemic, cognitive and constructivist). Data provided by each trainee varied in the total duration of the longitudinal evaluation (from 1 to 2 years of training) and in the number of longitudinal evaluation (SPRISTAD protocol expects that all trainees completed the questionnaires 4 times with 6-months intervals; however, they have had at least one experience in doing psychotherapy to complete all items of TCPR), reaching around 190 observations. In this study, the effect of time was evaluated 
considering the number of months since the beginning of psychotherapy training. We tested the effect of variables time, quality of supervision (perceived support in supervision and perceived critics in supervision), and personal therapy (yes $v s$ no), on the following TCPR dependent variables: perceived development items (perceived change, perceived improvement, perceived decline, overcoming limitations, satisfaction with development, and realization of potential as therapist), perceived skills and perceived difficulties in doing psychotherapy. Importantly, repeated-measures regressions analyses were used, with trainees and training institutes as random factors. Even if the number of participants was still exiguous, early results concerning the sensitivity of the TCPR questionnaire as an instrument to track change over time are now available and they appear to be promising. Most of the dependent variables- including perceived change, perceived improvement, overcoming part limitations, satisfaction with development, realization of potential, and therapeutic skills - significantly change over time. The quality of supervision confirmed to play a key role: perception of more support in supervision was predictive of most of the dependent variables (perceived change, perceived improvement, perceived decline, overcoming part limitations satisfaction with development, and therapeutic skills). Instead, compared to cross-sectional comparisons, the effect of having had a personal therapy on perceived development was less relevant, resulting as a significant predictor of overall change, but not associated with the other developmental variables more strictly associated with the training (such as perceived improvement, overcoming limitations, and realization of potential as therapist).

\section{Influences of trainees' background on their development}

As we mentioned before, the importance of evaluating trainees' background is related to the possibility to associate therapist characteristics and their development. In the Italian SPR conference in Palermo (Messina et al., 2018e), an additional step has been achieved with early exploration of the impact of personal background on trainees' perception of their development. We must specify that, at the present stage of SPRISTAD study, only preliminary analysis of an exiguous amount of data are available, and only for the Italian context. Thus, the data presented here should be considered very preliminary investigations.

In this case, the research question was: may trainees' background influence their development? To address this issue, two-years longitudinal data from 50 trainees that have completed both the TBIF and the TCPR have been considered. Probably due to the small sample, no significant associations were found between background variables and trainees' perceived development. However, an interesting exception was the lower rating of difficulties in having real empathy for patients in more traumatized trainees. This result is in line with the wounded healer hy- pothesis, but future studies should further focus on this hypothesis.

Another interesting result about the influence of trainees' personal life on their development concerns their current private life. Preliminary analyses (Messina et al., $2018 \mathrm{c}$ ) evaluated the association between current life and perceived development in a group of 68 trainees that have completed the TCPR, with at least two different longitudinal evaluations during a period of two years. According to such analyses, reported enthusiasms in doing psychotherapy was associated with satisfaction for actual life and emotional functioning, whereas the higher quality of current life was predictive of less disillusion about therapy and fewer difficulties in psychotherapy sessions. These results extend previous researches that have shown an important influence of therapists' current life on this sense of currently experienced professional growth, with alternate moments of enthusiasm and disillusion about therapy (Rønnestad \& Skovholt, 2003).

\section{Implication of preliminary data for research on trainees' development}

Taken together, results available from cross-actional and longitudinal investigations show enough sensitivity of the TCPR in the evaluation of differences between trainees at different steps of their training, as well as in the evaluation of changes over time in training. Moreover, both the detection of significant effects of time in training and the influences of trainees' background on their development are encouraging for the continuation of data collection on a large scale, implementing SPRISTAD online data collection.

Interesting insights concerning the core experiences of supervision and personal therapy come from reviewed preliminary data. With regard to supervision, the time in supervision perse appeared to be not relevant whereas the perceived quality of supervision (support $v s$ critics) is important. These results are in line with other studies which have suggested that supervisory alliance in supervision can be view as important as a therapeutic alliance in psychotherapy (Ladany, Ellis, \& Friedlander, 1999; RamosSánchez et al., 2002; Watkins, 2014) highlighting the importance of agreement between supervisor and trainee about task and goals (Rønnestad \& Skovholt, 2012). This information has relevant implications for training courses organization, suggesting that beyond the planning of supervision as part of training programs, the quality of the supervisory relationship deserve enormous attention in training. With this regard, more empirical and theoretical efforts are still required to define the characteristics of supervisory relationships that work.

Available data on the importance of personal therapy are still mixed. If in cross-sectional evaluations personal therapy emerged as an undeniable experience in therapist training, this result was smaller in longitudinal evaluation (probably due to the limited number of observations). Fu- 
ture studies should clarify this issue because of its possible contribution to the lively debate about mandatory personal therapy as part of psychotherapy training schools.

\section{Conclusions}

The Italian contribution to the collaborative longitudinal study of psychotherapy trainees' development promoted by SPRISTAD has been relevant for a preliminary test of SPRISTAD questionnaires sensitivity in assessing the constructs of interest. In the early findings described in the present paper, the TBIF was useful to describe trainees' characteristics such as their motivation, relational manner, and personal background which have shown to deserve attention in research on trainees' development. Similarly, the TCPR appeared suitable for the detection of cross-sectional differences in perceived development in trainees at different years of training, and for the detection of two-years longitudinal changes in trainees' perceived development.

Moreover, the significant results concerning trainees' development and associated variables provided early insights about the expected results of SPRISTAD study. Namely, early results seem to support the possibility to assess relevant changes in trainees during their training, and the potentiality of the study for the deepening the role of supervision and personal therapy as core aspects of training programs. Moreover, the clarification of associations between background and developmental variables has enormous potentiality in terms of trainees' selection and for the organization of training experiences.

In sum, our preliminary results are encouraging and lead us to strongly favor the continuation of the SPRISTAD data collection. In addition to the strengths of the reported studies, some critical issues connected to the future development of SPRISTAD study must be highlighted. First of all, the size of the samples which, although growing, is still very limited. Data collected so far cannot be considered as representative of the Italian situation and preliminary data coming from other countries have been not yet published (with the exception of recently published background data from Austria: Löffler-Stastka et al., 2018; Löffler-Stastka et al., 2019 in press; Tilkidzhieva et al., 2019). The very low number of schools that have joined the study can itself be thought of as a critical issue, as it perhaps signals an imperfect understanding of the potentiality that the study may have. These limitations will be overcome with the recently implemented online procedure for SPRISTAD data collection. The online procedure may ensure a large-scale data collection, which would provide also information concerning training programs in suitable samples and in widely different cultural contexts. In particular, the investigation of cultural differences is a core aspect which has lead to the implementation of SPRISTAD as an international multisite study. For example, future comparisons would clarify if training effectiveness varies between countries with different legal requirements to become a psychotherapist (Deurzen,2001).With regard to cultural differences, it was pointed out that while on the one hand, the adoption of a cross-country set of tools allows a more comparisons between the results, on the other hand, this does not allow us to catch and analyze the cultural specificities of the training programs in each country as well as the differences between the different theoretical and professional approaches.

A second advantage of the online data collection is that it may overcome the problem of the time required to complete questionnaires. A problem that has also been raised by participants. In this sense, the online procedure has several advantages in terms of time-consuming, but also in other technical aspects such as the precision of process of coding responses from paper-and-pencil format to a computer database, and the extreme facility in reaching trainees over the world.

Finally, the studies described in the present review are based on therapists self-reported perception of their performance in psychotherapy practice. This aspect can be considered a limitation because of the subjectivity of the data reported in the questionnaires. For this reason, as future steps of SPRISTAD project, new instruments for the evaluation of the supervisors' point of view and trainees' effectiveness in treating clinical cases should be implemented. At the same time, we outline that trainees' point of view is the most important for the evaluation of training program effectiveness. Alongside qualitative research with smaller datasets, large-scale research using self-report measures can provide strong data which may significantly influence training programs implementation and political decisions concerning the legal requirements for the profession of psychotherapists in all the world. To this aim, future developments of SPRISTAD study are fundamental to draw stronger conclusions concerning the preliminary insight described here.

\section{References}

Barnett, M. (2007). What brings you here? An exploration of the unconscious motivations of those who choose to train and work as psychotherapists and counsellors. Psychodynamic Practice, 13, 257-274. doi: 10.1080/14753630701455796

Barnfield, T. V., Mathieson, F. M., \& Beaumont, G. R. (2007). Assessing the development of competence during postgraduate cognitive-behavioral therapy training. Journal of Cognitive Psychotherapy, 21(2), 140-147. doi: 10.1891/ 088983907780851586

Bennett-Levy, J., \& Beedie, A. (2007). The ups and downs of cognitive therapy training: What happens to trainees' perception of their competence during a cognitive therapy training course? Behavioural and Cognitive Psychotherapy, 35(1), 61-75. doi: https://doi.org/10.1017/S1352465806003110

Deurzen, E. V. (2001). Psychotherapy training in Europe: similarities and differences. European Journal of Psychotherapy 
and Counselling, 4(3), 357-371. doi: 10.1080/13642530210 126275

EAP (2017).Italian situation of Psychotherapy - as per 2017.European Association for Psychotherapy. Available from: https://www.europsyche.org/contents/14307/italy

Farber, B. A., Manevich, I., Metzger, J., \& Saypol, E. (2005). Choosing psychotherapy as a career: Why did we cross that road? Journal of Clinical Psychology, 61, 1009-1031. doi:10.1002/jclp.20174

Giannone, F., Giordano, C., \& Di Blasi, M. (2015). Group psychotherapy in Italy. International Journal of Group Psychotherapy, 65(4), 501-511. doi:10.1521/ijgp.2015.65.4.501

Hill, C. E., \& Knox, S. (2013). Training and supervision in psychotherapy. In M. J. Lambert (Ed.), Bergin and Garfield's handbook of psychotherapy and behavior change (pp. 775811). Hoboken, NJ: John Wiley \& Sons.

Jung, C. (1951). Fundamental questions of psychotherapy. Princeton: Princeton University Press.

Ladany, N., Ellis, M. V., \& Friedlander, M. L. (1999). The supervisory working alliance, trainee self-efficacy, and satisfaction. Journal of Counseling \& Development, 77(4), 447-455. doi:10.1002/j.1556-6676.1999.tb02472.x

Löffler-Stastka, H., Gelo, O., Pleschberger, I., Hartmann, A., Orlinsky, D. E., Rønnestad, M. H., \& Willutzki, U. (2019). Psychotherapieausbildung in Österreich. Teil 1: Basisdaten und soziodemographische Hintergrunddatenaus der SPRISTADStudie [Psychotherapy training in Austria. Part 1: Baseline and socio-demographic background data from a SPRISTAD pilotstudy]. Zeitschrift für Psychosomatische Medizin und Psychotherapie [in press].

Löffler-Stastka, H., Gelo, O., Pleschberger, I., Schröder, T., Orlinsky, D. E., Rønnestad, M. H., \& Willutzki, U. (2018). Psychotherapieausbildung in Österreich. Teil 1: Basisdaten und soziodemographische Hintergrunddatenaus der SPRISTADStudie [Psychotherapy training in Austria. Part 1: Baseline and socio-demographic background data from a SPRISTAD pilot study]. Psychopraxis. Neuropraxis, 21(5), 227-231. doi: 10.1007/s00739-018-0508-9

McConnaughy, E. A. (1987). The person of the therapist in psychotherapeutic practice. Psychotherapy: Theory, Research, Practice and Training, 24(3), 303. doi:10.1037/h0085720

Messina, I., Gelo, O., Gullo, S., \& Orlinsky, D. (2018a). Predicting Perceived Development in Italian Trainees 'Experience of Therapeutic Work: preliminary Results of a two-year Longitudinal Evaluation. 49th International Annual Meeting SPR - Society of Psychotherapy Research, 27-30 June 2018, Amsterdam, Netherlands.

Messina, I., Salcuni, S., Gullo, S. \& Gelo, O. (2018b). Trainees' self evaluation of their development as psychotherapists: Early results of a longitudinal study. National Meeting SPRItaly - Italian section of Society of Psychotherapy Research, Palermo, Italia.

Messina, I., Gelo, O., Gullo, S., Sambin, M., Mosconi, A., Fenelli, A., ... \& Orlinsky, D. (2018c). Personal background, motivation and interpersonal style of psychotherapy trainees having different theoretical orientations: An Italian contribution to an international collaborative study on psychotherapy training. Counselling and Psychotherapy Research, 18(3), 299-307. doi:10.1002/capr.12176

Messina, I., Gelo, O., Sambin, M., Bianco, F., Mosconi, A., Fenelli, A., ...\& Orlinsky, D. (2017). Trainees self-evaluation of their development as psychotherapists: an Italian contribution to an international collaborative study on psychotherapy training. Clinical Psychology \& Psychotherapy, 25(2), 338-347. doi: 10.1002/cpp.2165

Messina, I., Gullo, S., Gelo, O., Salcuni, S., \& Giordano, C. (2018d). Personal background of trainees attending Italian psychotherapy training programs: a contribution to the SPRISTAD international study on therapists' development. 49th International Annual Meeting SPR - Society of Psychotherapy Research, 27-30 June 2018, Amsterdam, Netherlands.

Messina, I., Salcuni, S., Gullo, S. \& Gelo, O. (2018e). The person of the psychotherapy trainee: Influences of personal background and current life on perceived development as psychotherapist. National Meeting SPR-Italy - Italian section of Society of Psychotherapy Research, Palermo, Italia.

Messina, I., Solina, C., Arduin, A., Frangioni, V., Sambin, M., \& Gelso, C. (2018f). Origins of countertransference and core conflictual relationship theme of a psychotherapist in training as emerging in clinical supervision. Psychotherapy, 55(3), 222. doi:10.1037/pst0000148

Orlinsky, D., Ambühl, H., Rønnestad, M., Davis, J., Gerin, P., Davis, M., ... Aapro, N. (1999). Development of psychotherapists: Concepts, questions, and methods of a collaborative international study. Psychotherapy Research, 9(2), 127-153. doi: 10.1093/ptr/9.2.127

Orlinsky, D. E., Rønnestad, M. H., \& the SPR Collaborative Research Network (2005). How psychotherapists develop: A study of therapeutic work and professional development. Washington D.C.: American Psychological Association.

Orlinsky, D. E., Rønnestad, M. H., \& Willutzki, U. (2010). The SPR collaborative research program on the development of psychotherapists. In J. Norcross (Ed.), History of psychology: A century of change ( 2 nd ed.). Washington, D.C.: American Psychological Association.

Orlinsky, D. E., Strauss, B., Rønnestad, M. H., Hill, C. Castonguay, L., Willutzki, U., ... \& Carlsson, J. (2015). A collaborative study of development in psychotherapy trainees. Psychotherapy Bulletin, 50(4), 21-25.

Orlinsky, D. E., Willutzki, U., Rønnestad, M. H., \& Hartman, A. (in preparation). The organization and practice of collaborative research: Guidelines for participation in the SPRISTAD longitudinal study of psychotherapy trainee development.

Ramos-Sánchez, L., Esnil, E., Goodwin, A., Riggs, S., Touster, L. O., Wright, L. K., ... Rodolfa, E. (2002). Negative supervisory events: Effects on supervision and supervisory alliance. Professional Psychology: Research and Practice, 33(2), 197-202.

Rønnestad, M. H. \& Skovholt, T. M. (2003). The journey of the counselor and therapist: Research findings and perspectives on professional development. Journal of Career Development, 30, 5-44. doi:10.1177/089484530303000102

Rønnestad, M. H., \& Skovholt, T. M. (2012). The developing practitioner: Growth and stagnation of therapists and counselors. New York: Routledge.

Salcuni, S., Messina, I., Gullo, S. \& Gelo, O. (2018). Trainees' self evaluation of their development as psychotherapists: An update of spristad data collection in Italy. National Meeting SPR-Italy - Italian section of Society of Psychotherapy Research, Palermo, Italia.

Society for Psychotherapy Research (SPR), (2011). SPR Interest Section on Therapist Training and Development (SPRISTAD). Available from: https:/www.psychotherapyresearch.org/page/ SPRISTAD 
Tilkidzhieva, E., Gelo, O. C. G., Gullo, S., Orlinsky, D. E., Mörtl, K., \& Fiegl, J. (2019). Self-concept of relational skills in psychotherapy trainees: A pilot study. Counselling and Psychotherapy Research, 19(3), 311-320. doi:10.1002/ capr.12217
Watkins, C. E. Jr. (2014). The supervisory alliance: A half century of theory, practice, and research in critical perspective. American Journal of Psychotherapy, 68(1), 19-55. doi: 10.1176/appi.psychotherapy.2014.68.1.19 